\title{
Human IL-15 Inhibits NK Cells Specific for Human NK-92 Cells
}

\author{
HANS BERGMAN and CHRISTER LINDQVIST
}

Cell Biology Unit, Faculty of Natural Sciences and Engineering, Åbo Akademi University, Turku, Finland

\begin{abstract}
Background/Aim: Recent studies have indicated that natural killer $(N K)$ cells present in peripheral blood mononuclear cells (PBMCs) might be responsible for the somewhat poor outcome of clinical trials conducted with the $N K$ cell line NK-92, as well as chimeric antigen receptormodified NK-92 cells against leukemias and lymphomas. These NK cells and how their cytotoxic profiles can be altered by some common gamma chain receptor-dependent cytokines or by removal of $\mathrm{CD}^{+}$cells have been addressed herein. Materials and Methods: A time-resolved fluorometric assay using 2.2':6'.2"-terpyridine-6.6"-dicarboxylic acid-labeled NK-92 or K562 as target cells was used for measuring the cytotoxic activity of cytokine-treated PBMCs and purified NK cells. Results: Pre-incubation with $25 \mathrm{ng} / \mathrm{ml}$ interleukin 12 (IL12), IL-15 or IL-21 for $72 \mathrm{~h}$ increased NK cell activity against K562 cells by more than 90\% (1:25 target:effector ratio), whereas the corresponding NK cell activity against NK-92 cells was reduced by $15.9 \pm 0.1 \%$ by $I L-12$ and $50.6 \pm 2.9 \%$ by IL-15 compared to cells treated with medium alone. IL-7, on the other hand, increased NK activity against K562 to a much smaller extent $(10.4 \pm 0.4 \%)$ and inhibited $N K-92$ cell lysis by $15.2 \pm 0.3 \%$. Interestingly, similar amounts of $I L-2$ potentiated NK cell activity against both $\mathrm{K} 562$ and NK-92 cells by $50.9 \pm 0.5 \%$ and $14.3 \pm 0.9 \%$, respectively. Purification of $N K$ cells with magnetic beads demonstrated that NK cells indeed were responsible for the observed cytotoxic activity against both NK-92 cells $(58.5 \pm 9.10 \%, 1: 100$ target:effector ratio) and K562 cells $(81.6 \pm 9.57 \%, 1: 100$ target:effector ratio). Elimination of CD4+ cells from PBMCs did not alter the NK
\end{abstract}

This article is freely accessible online.

Correspondence to: Christer Lindqvist, Cell Biology, Faculty of Natural Sciences and Engineering, Åbo Akademi University, Tykistökatu 6, FIN-20520, Turku, Finland. Tel.: +358 22154053, e-mail: clindqvi@abo.fi

Key Words: Natural killer cells, lysis, magnetic beads, NK-92, K562, PBMC activity profile. Conclusion: This study highlights a problem that might arise with immune-based NK-92 and chimeric antigen receptor-transduced NK-92 cell therapies and pinpoints the need for evaluating new NK-like cell lines.

Natural killer (NK) cells belong to the innate immune system and have the ability to kill some tumor as well as virally infected cells without prior sensitization (1). This cell type was identified by Kiessling et al. (2) and Herberman et al. (3) in 1975 and comprises $5 \%$ to $15 \%$ of peripheral blood lymphocytes (2-4). NK cell-mediated cytotoxicity is accomplished by different killer activation receptors (KARs) and killer inhibitory receptors (KIRs) expressed on their surface (5). If the activation receptors (or the majority of them) are not triggered by corresponding ligands on the target cell, no lysis will occur. On the contrary, if the inhibitory receptors are not activated due to low or no expression of human leukocyte antigen class I antigens on the target cell, the cell will be lysed (6).

Since the discovery of NK cells, different efforts have been made in order to exploit these cells for clinical purposes (7). However, there are several problems to be overcome with respect to the cytotoxic potency of NK cells prepared from PBMCs (8). This has forced scientists to utilize NK cell lines in NK cell-based immunotherapies and the NK-92 cell line is so far the only Food and Drug Administration-approved NK cell line to be used in clinical trials $(7,9,10)$. Phase I clinical trials were also recently conducted with CD33-modified chimeric antigen receptor (CAR)-modified NK-92 cells in an effort to provide the first 'off-the-shelf' cellular products for the treatment of cancer (11). However, it was recently demonstrated that NK-92 cells are themselves in fact susceptible target cells for PBMCs prepared from normal healthy individuals (12). This is an observation that might even pull the rug out from under NK-92 cell-based clinical trials.

In an effort to determine whether this target cell discrepancy could be manipulated, in this study PBMCs were treated with different common gamma chain receptordependent cytokines. The importance of these findings, including a possible role of T-regulatory $\left(\mathrm{T}_{\text {reg }}\right)$ cells is analyzed and discussed. 


\section{Materials and Methods}

Reagents. Recombinant human interleukin 2 (IL-2), IL-4, IL-7, IL15 and IL-21 were purchased from PeproTech EC (London, UK).

Cells and cell lines. The human NK cell line NK-92 (ImmuneMedicine, Inc. Vancouver, Canada) and the human erythroleukemia NK-sensitive target cell line $\mathrm{K} 562$ were cultured at $37^{\circ} \mathrm{C}$ in Roswell Park Memorial Institute 1640 (RPMI 1640) medium $\left(\mathrm{GIBCO}^{\mathrm{TM}}\right.$, Invitrogen Corp., Paisley, UK) plus $5 \%$ fetal calf serum (FCS; GIBCO $^{\text {TM }}$ ) supplemented with $2 \mathrm{mM} \mathrm{L}$-glutamine, $10 \mathrm{U} / \mathrm{ml}$ penicillin $\mathrm{G}$ sodium salt and 10 $\mu \mathrm{g} / \mathrm{ml}$ streptomycin sulphate (GIBCO ${ }^{\mathrm{TM}}$ ) in a $95 \%$ humidified chamber with $5 \% \mathrm{CO}_{2}$ (13-14). The culture medium of the NK-92 cell line was always supplemented with $20 \mathrm{U} / \mathrm{ml}$ of IL-2 but this was not present in the killing assays. PBMCs were isolated from blood donated by healthy volunteers (Finnish Red Cross Blood Service) by density gradient centrifugation on Ficoll-Paque density gradient media (GE Healthcare Life Sciences, Fairfield, CT, USA).

Treatment of PBMCs with cytokines. PBMCs $\left(1 \times 10^{6} / \mathrm{ml}\right)$ were pretreated in RPMI 1640 plus $5 \%$ FCS with or without $25 \mathrm{ng} / \mathrm{ml}$ of IL2, IL-4, IL-7, IL-15 or IL-21 for $72 \mathrm{~h}$, before their NK activities were tested against NK-92 and K562 cells. Results are indicated as the percentage change in cell lysis compared to PBMCs treated with medium alone.

Purification of human NK cells from PBMCs with magnetic beads. Human NK cells were isolated using Dynabeads Untouched Human NK Cells Kit (Invitrogen, Carlsbad, CA, USA) according to the protocol provided by the manufacturer. In brief, beads were first washed with an isolation buffer $\left(\mathrm{Ca}^{2+}\right.$ - and $\mathrm{Mg}^{2+}$-free phosphatebuffered saline) supplemented with $2 \%$ FCS and 2 mM EDTA. Isolated PBMCs, pretreated with heat-inactivated FCS, were thereafter labelled with an antibody mix consisting of biotinylated monoclonal antibodies towards human CD3, CD14, human leukocyte antigen class II, CD123 and CD235 (20 min, $4^{\circ} \mathrm{C}$ ). Antibody-labeled PBMCs were finally washed with the isolation buffer, before being mixed and incubated with the pre-washed beads (gentle tilting and rotation of the tube for $15 \mathrm{~min}$ at room temperature). The bead-bound cells were then resuspended carefully before the tube was placed under a magnetic field for $2 \mathrm{~min}$. The supernatant containing purified NK cells was transferred to a new tube and the collected cells were finally washed and cultured in RPMI 1640 plus $5 \%$ FCS $\left(1 \times 10^{6}\right.$ cells/ml $)$ for $48 \mathrm{~h}$.

Removal of $\mathrm{CD}^{+}$cells from PBMCs with magnetic beads. Human CD4+ T-cells were depleted from the PBMC cell suspension using anti-CD4-labelled magnetic beads (Invitrogen) according to the protocol provided by the manufacturer. In brief, beads were first washed with an isolation buffer $\left(\mathrm{Ca}^{2+}\right.$ - and $\mathrm{Mg}^{2+}$-free phosphatebuffered saline supplemented with $2 \%$ FCS and 2 mM EDTA). PBMCs, suspended in the same buffer, were transferred to a tube containing the washed anti-CD4-labeled beads $(500 \mu \mathrm{l}$ beads $/ 100 \times 10^{6}$ cells) and incubated in a rotation device for $30 \mathrm{~min}$ $\left(+4^{\circ} \mathrm{C}\right)$. The tube was thereafter placed under a magnetic field for 3 min and cells not bound to the magnet were collected and considered as $\mathrm{CD}^{-}{ }^{-}$PBMCs.

Labeling of target cells with benzophenone tetracarboxylic dianhydride (BATDA). K562 or NK-92 target cells $\left(1 \times 10^{6}\right.$ in $1 \mathrm{ml}$

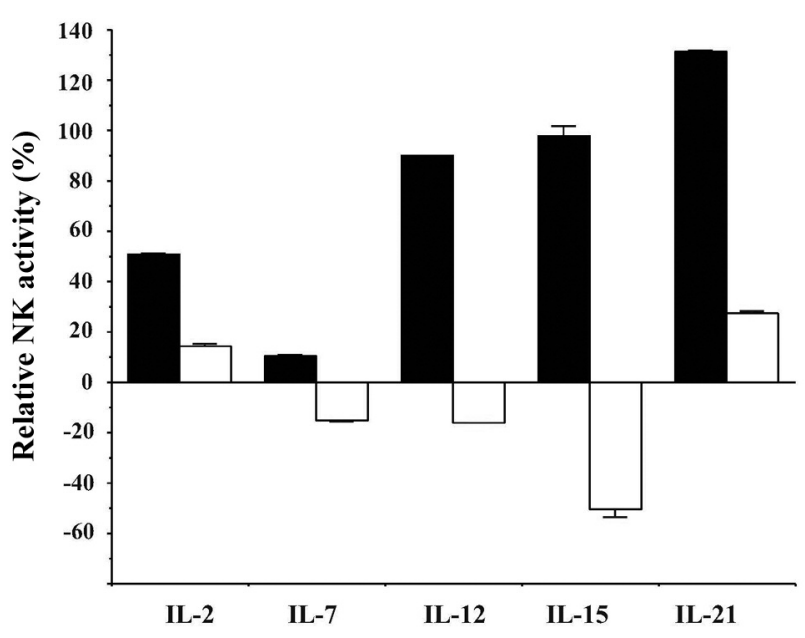

Figure 1. Relative peripheral blood mononuclear cell- mediated natural killer cytotoxic activity against NK-92 cells upon 72 h stimulation with interleukin (IL). K562 cells (filled bars) or NK-92 cells (open bars) were used as target cells. Results are expressed as means $\pm S D(N=3)$.

RPMI 1640 plus 5\% FCS) were first pre-incubated for $15 \mathrm{~min}$ at $37^{\circ} \mathrm{C}$ before incubation with $20 \mu \mathrm{M}$ BATDA (PerkinElmer, Inc., Wellesley, MA, USA) for $25 \mathrm{~min}$ at $37^{\circ} \mathrm{C}$. The cells were finally washed four times in RPMI 1640 plus 5\% FCS with mild centrifugation $(306 \times g, 2 \mathrm{~min})$ and adjusted to $5 \times 10^{4}$ cells $/ \mathrm{ml}$ before being mixed with the effector cells.

Cytotoxicity assay. The cytotoxicity assay was, with minor modifications, performed as described earlier (15). In brief, serial dilutions of PBMCs depleted of $\mathrm{CD}^{+}{ }^{+}$cells or purified NK cells in $100 \mu \mathrm{l} /$ well (in triplicates) were added to v-bottomed 96-well microtiter plates (Sarstedt Inc, Nümbrecht, Germany). Target to effector (T:E) ratios ranged from $1: 100$ to $1: 12.5$ following the addition of $100 \mu \mathrm{l}\left(5 \times 10^{3}\right)$ of target cells to each well. Following a short centrifugation $(34 \times g, 1 \mathrm{~min})$, the co-cultures were incubated for $2 \mathrm{~h}$ at $37^{\circ} \mathrm{C}$ in a $95 \%$ humidified chamber with $5 \% \mathrm{CO}_{2}$. They were then centrifuged for $5 \mathrm{~min}(688 \times g)$, and $20 \mu \mathrm{l}$ of supernatant from each well were removed and added to $100 \mu \mathrm{l}$ europium solution (Perkin Elmer, Inc.) contained within black flat-bottomed 96-well Costar plates (Corning Inc., Corning, NY, USA). The spontaneous europium release was determined by incubating the target cells in the culture medium alone instead of having effector cells added, and the maximum europium release was determined by incubating the target cells in the same medium with $0.05 \%$ Triton $\mathrm{X}-100$. The plates containing europium and the co-culture supernatants were finally shaken for $15 \mathrm{~min}$ and the fluorescence of the europium-TDA chelates formed was measured using a 1420 Victor multi-label counter (PerkinElmer Inc.). The percentage of specific release was calculated using the following formula:

(Experimental release - spontaneous release)

Specific release $=\frac{(\text { Maximum release }- \text { spontaneous release }) \times 100 \%}{(\text { axp }}$ 
Table I. Natural killer activity (\% lysis) against NK-92 and K562 cells using peripheral blood mononuclear cells (PMBCs) and purified NK cells.

\begin{tabular}{|c|c|c|c|c|c|}
\hline \multirow[b]{2}{*}{ Target cells } & \multirow[b]{2}{*}{ Effector cells } & \multicolumn{4}{|c|}{ Target:Effector cell ratio } \\
\hline & & $1: 100$ & $1: 50$ & $1: 25$ & $1: 12.5$ \\
\hline K562 & PBMCs & $39.5 \pm 1.16$ & $23.3 \pm 1.15$ & $15.9 \pm 1.12$ & $11.1 \pm 1.58$ \\
\hline NK-92 & PBMCs & $20.8 \pm 1.24$ & $18.2 \pm 0.15$ & $10.1 \pm 0.73$ & $11.4 \pm 1.51$ \\
\hline K562 & Purified NK cells & $81.6 \pm 9.57$ & $60.3 \pm 5.66$ & $40.2 \pm 1.87$ & $25.7 \pm 2.18$ \\
\hline NK-92 & Purified NK cells & $58.5 \pm 9.10$ & $36.9 \pm 3.70$ & $20.0 \pm 3.40$ & $16.5 \pm 3.04$ \\
\hline
\end{tabular}

Data are expressed as means $\pm \mathrm{SD}$ and are representative of three independent experiments.

\section{Results}

IL-12 and IL-15 potentiate NK cell activity against K562 cells but inhibit the NK activity of PBMCs against NK92 cells. Treatment of PBMCs with $25 \mathrm{ng} / \mathrm{ml} \mathrm{IL-12}$ or IL-15 for $72 \mathrm{~h}$, compared to medium alone, increased their NK activity against K562 cells (T:E ratio 1:25) with $90.0 \pm 0.1 \%$ and $97.9 \pm 3.7 \%$, respectively (Figure 1). However, replacing K562 cells with NK92 cells reduced the cytotoxic activity, with $15.9 \pm 0.1 \%$ for IL-12 and $50.6 \pm 2.9 \%$ with IL-15 compared to medium-treated PBMCs. Similar findings, but to a smaller extent, were noted with IL-7. Both IL-2 and IL21 increased NK cell activity against NK92 as well as K562 cells. Interestingly, IL-21 increased the killing activity of PBMCs against K562 cells to $131.5 \pm 0.3 \%$, compared to culturing them in medium alone for $72 \mathrm{~h}$ (Figure 1). Similar trends for all cytokines tested at other T:E ratios were found (data not shown).

Purified NK cells kill NK-92 cells. Table I shows the NK activity against K562 and NK-92 cells using NK cells purified with magnetic beads. NK activity increased to approximately 2.5 -fold when K562 cells were incubated with purified NK cells in a 1:50 ratio. For NK-92 cells, lysis increased approximately twofold. As observed previously with PBMCs (12), when purified NK cells were cultured for 48 to $72 \mathrm{~h}$ in medium, similarly high NK activities against both target cells were observed (data not shown).

Similar cytotoxic behavior of PBMCs and PBMCs depleted of $\mathrm{CD}^{+}$cells. The findings shown in Table I that PBMCs as well as purified NK cells lyse both NK-92 and K562 cells equally well upon 48 to $72 \mathrm{~h}$ culture in medium alone is intriguing. In an effort to find out whether NK cells specific for NK-92 cells are under some type of regulation, we next depleted PBMCs of CD4+ cells using magnetic beads. For a 1:100 T:E ratio, the percentage lysed NK-92 cells increased from $35.2 \pm 3.96 \%$ using PBMCs to $63.0 \pm 0.56 \%$ using $\mathrm{CD}^{+}{ }^{+}$ depleted PBMCs. The corresponding values with K562 as target cells changed from $51.8 \pm 1.98 \%$ lysed cells to

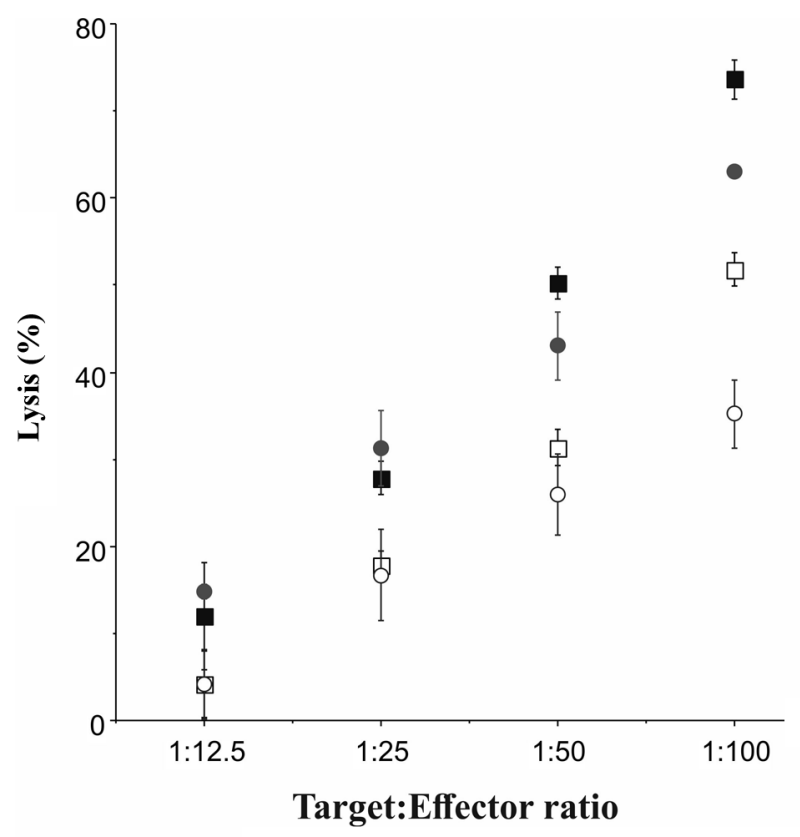

Figure 2. Comparison of the cytotoxic activity of native (open symbols) and $\mathrm{CD}^{+}$-depleted (closed symbols) peripheral blood mononuclear cells as effector cells against target K562 cells (squares) and NK-92 cells (circles). Results are expressed as means $\pm S D(N=3)$.

$73.6 \pm 2.30 \%$. Experiments conducted at other T:E ratios and with effector cells cultured for $48 \mathrm{~h}$ in medium showed a similar lysis pattern (Figure 2).

\section{Discussion}

NK-92 and CAR-NK-92 cells in particular are cellular tools that in the near future might have potential for treating different forms of cancer. As summarized by Kloess et al. (16), several phase I and II clinical trials have already been conducted, but there are also many ongoing trials against diseases such as lymphoma, leukemia and glioblastoma. The reports available 
from these clinical trials have unfortunately so far not been that encouraging and a partial explanation for these dissatisfactory results was recently given by Bergman et al. (12). In that study, it was demonstrated that NK-92 cells were easily killed by PBMCs isolated from blood donated by healthy volunteers. A pre-incubation for 48-72 $\mathrm{h}$ in normal culture medium enhanced the NK cell activity against these cells even further, reaching similar cytolysis levels as for K562 cells.

Despite the earlier reported observation that no prior sensitization was needed in order for PBMCs to lyse NK-92 cells (12), it was still of interest to verify that NK cells were in fact responsible for the observed cytolysis. Data presented in Table I shows that NK cells purified with magnetic beads exhibited increased cytotoxic activity $(58.5 \pm 9.10 \%)$ against NK-92 cells (1:100 T:E ratio) compared with the unpurified counterpart (20.8\%). As expected, using K562 cells as target cells, a similar lysis pattern was observed.

Since it was demonstrated that NK cells are active players in cytotoxic reactions with NK-92 cells as target cells (Table I), it was of interest to analyze whether cytokine treatment of PBMCs would alter cell lysis in a similar fashion as has been reported for K562 cells. Interestingly, the common gamma chain receptor-dependent cytokines studied here can be divided into two different groups: IL-2 and IL-21, which potentiated NK cell activity against both target cell lines; and IL-7, IL-12, and IL-15, which potentiated NK cell activity against K562 cells but inhibited that against NK-92 cells (Figure 1). One explanation for this discrepancy might be cytokine-induced expression of KIRs or KARs, or alternatively, down-regulation of some of these receptors. There appears to be an alteration that results in a change in overall T:E cell-binding properties, leading also to a change in the balance between these competing "kill" and "do not kill" signals. Cytokine-mediated alterations in KIR and KAR expression levels have been described by Ewen et al. (17).

$\mathrm{T}_{\text {reg }}$ cells, which can be subdivided into natural and induced $\mathrm{T}_{\text {reg }}$ cells, are part of the adaptive immune system and have been reported to suppress NK cells $(18,19)$. Data presented in Figure 2 show that removing $\mathrm{CD}^{+}$cells, including $\mathrm{T}_{\text {reg }}$ cells, from the PBMC population led to a similar increase in NK activity against both target cell lines. This observation indicates that the increase in NK activity against NK-92 cells (in the comparison between using CD4 ${ }^{+}$depleted PBMCs pre-incubated for $48 \mathrm{~h}$ and those without any pre-incubation) is not directly mediated by $\mathrm{T}_{\text {reg }}$ cells.

Additional studies are of importance in characterizing these NK cells, their regulation and mechanism of action, with respect to ongoing and future clinical studies with NK92 or CAR NK-92 cells. However, the data presented here do not favor the feasibility of NK-92 cell-based immunotherapies, instead they further indicate that other NK or NK-like cell lines such as YT might be more relevant for use in adoptive immunotherapies.

\section{Conflicts of Interest}

The Authors declare no conflicts of interest regarding this study.

\section{Authors' Contributions}

$\mathrm{HB}$, performed the majority of the experiments and contributed to the writing of the article. CL performed part of the experiments and contributed to the writing of the article. The Authors discussed the results and contributed to the final article.

\section{References}

1 Trinchieri G: Biology of natural killer cells. Adv Immunol 47: 187376, 1989. PMID: 2683611. DOI: 10.1016/s0065-2776(08)60664-1

2 Kiessling R, Klein E and Wigzell H: "Natural" killer cells in the mouse. I. Cytotoxic cells with specificity for mouse Moloney leukemia cells. Specificity and distribution according to genotype. Eur J Immunol 5(2): 112-117, 1975. PMID: 1234049. DOI: $10.1002 /$ eji.1830050208

3 Herberman RB, Nunn ME and Lavrin DH: Natural cytotoxic reactivity of mouse lymphoid cells against syngeneic acid allogeneic tumors. I. Distribution of reactivity and specificity. Int J Cancer 16(2): 216-229, 1975. PMID: 50294. DOI: 10.1002/ijc.2910160204

4 Campbell KS and Hasegawa J: Natural killer cell biology: an update and future directions. J Allergy Clin Immunol 132(3): 536544, 2013. PMID: 23906377. DOI: 10.1016/j.jaci.2013.07.006

5 Long EO: Regulation of immune responses through inhibitory receptors. Annu Rev Immunol 17: 875-904, 1999. PMID: 10358776. DOI: 10.1146/annurev.immunol.17.1.875

6 Kirwan S and Burshtyn D: Regulation of natural killer cell activity. Current Opinion in Immunology 19(1): 46-54, 2019. DOI: 10.1016/j.coi.2006.11.012

7 Klingemann H, Boissel L and Toneguzzo F: Natural killer cells for immunotherapy - Advantages of the NK-92 cell line over blood NK cells. Front Immunol 7: 91, 2016. PMID: 27014270. DOI: 10.3389/fimmu.2016.00091

8 Klingemann HG and Martinson J: Ex vivo expansion of natural killer cells for clinical applications. Cytotherapy 6(1): 15-22, 2004. PMID: 14985163. DOI: 10.1080/14653240310004548

9 Galluzzi L, Vacchelli E, Bravo-San Pedro JM, Buqué A, Senovilla L, Baracco EE, Bloy N, Castoldi F, Abastado JP, Agostinis P, Apte RN, Aranda F, Ayyoub M, Beckhove P, Blay JY, Bracci L, Caignard A, Castelli C, Cavallo F, Celis E, Cerundolo V, Clayton A, Colombo MP, Coussens L, Dhodapkar MV, Eggermont AM, Fearon DT, Fridman WH, Fučíková J, Gabrilovich DI, Galon J, Garg A, Ghiringhelli F, Giaccone G, Gilboa E, Gnjatic S, Hoos A, Hosmalin A, Jäger D, Kalinski P, Kärre K, Kepp O, Kiessling R, Kirkwood JM, Klein E, Knuth A, Lewis CE, Liblau R, Lotze MT, Lugli E, Mach JP, Mattei F, Mavilio D, Melero I, Melief CJ, Mittendorf EA, Moretta L, Odunsi A, Okada H, Palucka AK, Peter ME, Pienta KJ, Porgador A, Prendergast GC, Rabinovich GA, Restifo NP, Rizvi N, Sautès-Fridman C, Schreiber H, Seliger B, Shiku H, SilvaSantos B, Smyth MJ, Speiser DE, Spisek R, Srivastava PK, Talmadge JE, Tartour E, Van Der Burg SH, Van Den Eynde BJ, Vile R, Wagner H, Weber JS, Whiteside TL, Wolchok JD, Zitvogel L, Zou W and Kroemer G: Classification of current 
anticancer immunotherapies. Oncotarget 5(24): 12472-12508, 2014. PMID: 25537519. DOI: 10.18632/oncotarget.2998

10 Suck G, Odendahl M, Nowakowska P, Seidl C, Wels WS, Klingemann HG and Tonn T: NK-92: an 'off-the-shelf therapeutic' for adoptive natural killer cell-based cancer immunotherapy. Cancer Immunol Immunother 65(4): 485-492, 2016. PMID: 26559813. DOI: 10.1007/s00262-015-1761-x

11 Tang X, Yang L, Li Z, Nalin AP, Dai H, Xu T, Yin J, You F, Zhu M, Shen W, Chen G, Zhu X, Wu D and Yu J: Erratum: First-inman clinical trial of CAR NK-92 cells: safety test of CD33-CAR NK-92 cells in patients with relapsed and refractory acute myeloid leukemia. Am J Cancer Res 8(9): 1899, 2018. PMID: 30323981 .

12 Bergman H, Sissala N, HÄgerstrand $\mathrm{H}$ and Lindqvist C: Human NK-92 cells function as target cells for human NK cells Implications for CAR NK-92 therapies. Anticancer Res 40(10): 5355-5359, 2020. PMID: 32988854. DOI: 10.21873/anticanres. 14543

13 Gong JH, Maki G and Klingemann HG: Characterization of a human cell line (NK-92) with phenotypical and functional characteristics of activated natural killer cells. Leukemia $8(4)$ : 652-658, 1994. PMID: 8152260.

14 Lozzio CB and Lozzio BB: Human chronic myelogenous leukemia cell-line with positive Philadelphia chromosome. Blood 45(3): 321-334, 1975. PMID: 163658.

15 Blomberg K, Hautala R, Lövgren J, Mukkala VM, Lindqvist C and Akerman K: Time-resolved fluorometric assay for natural killer activity using target cells labelled with a fluorescence enhancing ligand. J Immunol Methods 193(2): 199-206, 1996. PMID: 8699033. DOI: 10.1016/0022-1759(96)00063-4
16 Kloess S, Kretschmer A, Stahl L, Fricke S and Koehl U: CARexpressing natural killer cells for cancer retargeting. Transfus Med Hemother 46(1): 4-13, 2019. PMID: 31244577. DOI: $10.1159 / 000495771$

17 Ewen EM, Pahl JHW, Miller M, Watzl C and Cerwenka A: KIR downregulation by IL-12/15/18 unleashes human NK cells from KIR/HLA-I inhibition and enhances killing of tumor cells. Eur J Immunol 48(2): 355-365, 2018. PMID: 29105756. DOI: 10.1002/eji.201747128

18 Ralainirina N, Poli A, Michel T, Poos L, Andrès E, Hentges F and Zimmer J: Control of NK cell functions by CD4+CD25+ regulatory T cells. J Leukoc Biol 81(1): 144-153, 2007. PMID: 16959895. DOI: $10.1189 / \mathrm{jlb} .0606409$

19 Pedroza-Pacheco I, Madrigal A and Saudemont A: Interaction between natural killer cells and regulatory $\mathrm{T}$ cells: perspectives for immunotherapy. Cell Mol Immunol 10(3): 222-229, 2013. PMID: 23524654. DOI: 10.1038/cmi.2013.2
Received May 4, 2021

Revised May 27, 2021

Accepted May 31, 2021 